MUCOSAL IMMUNOLOGY

\title{
Intestinal epithelial exosomes carry MHC class II/peptides able to inform the immune system in mice
}

\author{
G Van Niel, J Mallegol, C Bevilacqua, C Candalh, S Brugière, E Tomaskovic-Crook, J K Heath, \\ N Cerf-Bensussan, M Heyman
}

See end of article for authors' affiliations

.....................

Correspondence to: Dr M Heyman, INSERM EMI 0212, Faculté Necker-Enfants Malades, 156 rue de Vaugirard, 75730 Paris Cedex 15 France; heyman@necker.fr

Accepted for publication 23 July 2003
Background: Intestinal epithelial cells secrete exosome-like vesicles. The aim of this study was to characterise murine intestinal epithelial exosomes and to analyse their capacity to inform the immune system in vivo in mice.

Methods: Epithelial exosomes were obtained from the murine epithelial cell line MODE K incubated in the presence or absence of interferon $\gamma($ IFN- $\gamma$ ) together with pepsin/trypsin ovalbumin hydrolysate (hOVA) to mimic luminal digestion. Exosomes isolated from MODE K conditioned media (EXO-hOVA and EXOhOVA-IFN) were characterised by western blot, peptide mapping, and mass spectrometry. They were injected intraperitoneally to $\mathrm{C} 3 \mathrm{H} / \mathrm{HeN}$ mice to test their immunocompetence.

Results: MODE K epithelial exosomes displayed major histocompatibility complex (MHC) class I and class II (upregulated by IFN- $\gamma$ ) molecules and tetraspan proteins (CD9, CD81, CD82) potentially involved in the binding to target cells. A33 antigen, an lg-like molecule highly specific for intestinal epithelial cells, was enriched in exosomes and was also found in mice mesenteric lymph nodes, suggesting exosome migration towards the gut associated lymphoid tissues. Intraperitoneal injection of EXO-hOVA or EXO-hOVA-IFN did not induce humoral or cellular tolerance to OVA in mice. In contrast, exosomes obtained after incubation with IFN- $\gamma$ (EXO-hOVA-IFN), bearing abundant MHC class II/OVA complexes, induced a specific humoral immune response.

Conclusions: Epithelial exosomes are antigen presenting vesicles bearing MHC class II/peptide complexes that prime for an immunogenic rather than tolerogenic response in the context of a systemic challenge. In the intestine, both the mucosal microenvironment and local effector cells are probably key players in determining the outcome of the immune response to exosome derived epitopes.
$\mathrm{T}$ he high concentration of foreign antigens present in the gut lumen is separated from the local intestinal immune system by a single layer of polarised epithelial cells. Intestinal epithelial cells (IEC) can endocytose dietary proteins, process them into peptides, ${ }^{1}$ and in vitro can present these peptides to $\mathrm{CD}^{+} \mathrm{T}$ lymphocytes, particularly when major histocompatibility complex (MHC) class II molecules are upregulated, ${ }^{2-4}$ and in the presence of accessory molecules. $^{56}$ However, in vivo, direct interactions between IEC and $\mathrm{CD}^{+} \mathrm{T}$ cells predominating in the lamina propria are limited due to the presence of the basement membrane. IEC have been shown to release exosome-like vesicles ${ }^{7}$ morphologically similar to the exosomes secreted by professional antigen presenting cells (APC) such as B cells ${ }^{8}$ or dendritic cells. ${ }^{9}$ Epithelial exosomes released from basolateral sides of IEC bear high amounts of MHC class I and class II molecules, suggesting that they may interact with the underlying immune system. They also contain A33 antigen, ${ }^{7}$ a molecule whose expression is restricted essentially to the intestinal epithelium. ${ }^{10}{ }^{11}$ Exosomes derived from professional APC moderately activate $\mathrm{CD}^{8}$ or $\mathrm{CD}^{12} \mathrm{~T}$ lymphocytes, and it was recently shown that their antigen presenting capacity highly depended upon dendritic cells, ${ }^{14}$ suggesting that exosomes have to be taken up by professional APC to induce efficient $\mathrm{T}$ cell activation. They may therefore be involved in the rapid dissemination of immune information via APC.

In the present study, we tested the hypothesis that intestinal epithelial exosomes bearing MHC class II/ovalbumin (OVA) peptide complexes, generated in the presence of interferon $\gamma($ IFN- $\gamma)$ and OVA that had been predigested with gastric and pancreatic enzymes, can transmit immune information and thereby act as sensors of the antigenic information present in the intestinal lumen. Murine IEC derived exosomes were characterised and their interaction with the immune system was tested in vivo in mice. We tested the possibility that intraperitoneal injection of OVA loaded epithelial exosomes could either: (1) mimic oral ingestion of OVA and inhibit specific humoral and/or cellular immune responses (oral tolerance), as previously suggested ${ }^{15}$ or (2) directly prime the humoral immune response to OVA (sensitisation).

\section{METHODS}

\section{Antigens}

We incubated epithelial cells in the presence of OVA that had been predigested with pepsin and trypsin to mimic the fate of this protein in the intestinal lumen. OVA $10 \mathrm{mg} / \mathrm{ml}$ was treated for four hours $\left(37^{\circ} \mathrm{C}, \mathrm{pH} 1.8\right)$ with pepsin $(20 \mathrm{mg} / \mathrm{g}$ protein; Sigma, St Louis, Missouri, USA) and trypsin (20 mg/g protein) at $\mathrm{pH} 7.8$. Enzymes were inactivated for 45 minutes at $85^{\circ} \mathrm{C}$ and eliminated by ultrafiltration on membranes retaining molecules greater than $10000 \mathrm{Da}$

\footnotetext{
Abbreviations: IFN- $\gamma$, interferon $\gamma$; APC, antigen presenting cell; IEC, intestinal epithelial cells; OVA, ovalbumin; hOVA, ovalbumin hydrolysate; MHC, major histocompatibility complex; MALDI-TOF-MS, matrix assisted laser desorption ionisation-time of flight-mass spectrometry; DMEM, Dulbecco's modified Eagle's medium; MLN, mesenteric lymph nodes; SDS-PAGE, sodium dodecyl sulphatepolyacrylamide gel electrophoresis; CFA, complete Freund's adjuvant; DTH, delayed type hypersensitivity; PBS, phosphate buffered saline
} 
(centriplus,YM10; Millipore, St Quentin en Yuelines, France) The filtrate, referred to as ovalbumin hydrolysate (hOVA), was sterilised and frozen until use.

\section{Murine intestinal epithelial cell line (MODE K)}

The murine intestinal epithelial cell line MODE $\mathrm{K}^{16}$ kindly provided by D Kaiserlian, was used. This cell line is derived from $\mathrm{C} 3 \mathrm{H} / \mathrm{He}$ mice and expresses $\mathrm{I}^{\mathrm{k}} \mathrm{A}^{\mathrm{k}} \mathrm{MHC}$ class II molecules. Cells were cultured in Dulbecco's modified Eagle's medium (DMEM; Gibco, Life Technologies, CergyPontoise, France) containing 10\% heat inactivated fetal calf serum, $4 \mathrm{mM}$ glutamine, and $50 \mu \mathrm{g} / \mathrm{ml}$ gentamicin, in a humidified atmosphere of $5 \% \mathrm{CO}_{2} / 95 \%$ air.

\section{Exosome preparation from MODE K epithelial cell line conditioned media}

MODE K cells were seeded $\left(5 \times 10^{6}\right.$ cells $)$ into $75 \mathrm{~cm}^{2}$ Falcon flasks in DMEM containing $10 \%$ Prolifix (synthetic serum; Biomedia, France), $4 \mathrm{mM}$ glutamine, $50 \mu \mathrm{g} / \mathrm{ml}$ gentamicin, and OVA $(10 \mu \mathrm{M})$ or OVA predigested with pepsin and trypsin to mimic degradation in the intestinal lumen (hOVA corresponding to $10 \mu \mathrm{M}$ OVA). Four days later, cell supernatants were collected to isolate exosomes under basal conditions (EXO-OVA or EXO-hOVA). To obtain exosomes from MHC class II enriched enterocytes, MODE K cells were further incubated for 48 hours with OVA or hOVA in the presence of murine IFN- $\gamma(100 \mathrm{U} / \mathrm{ml})$ before exosomes were collected (EXO-OVA-IFN or EXO-hOVA-IFN). Exosomes obtained under basal and IFN- $\gamma$ conditions were isolated and quantified as previously described. ${ }^{7}$ Generally, $10 \mu \mathrm{g}$ MODE K exosomes were collected from the 48 hour conditioned medium from a $75 \mathrm{~cm}^{2}$ culture flask.

In some experiments, exosomes were isolated from human or mice serum to analyse whether intestinal epithelial exosomes can access the peripheral blood stream. Serum exosomal protein content was estimated by western blot analysis using the A33 antigen, a specific marker of intestinal epithelial exosomes.

\section{Identification of epithelial exosomes in mouse mesenteric lymph nodes}

We looked for the presence of A33 antigen in mesenteric lymph nodes (MLN) to test the hypothesis that epithelial exosomes released at the basal pole of enterocytes can migrate (alone or bound to dendritic cells) towards these secondary lymphoid organs. As A33 antigen is highly expressed in IEC, ${ }^{11}$ a comparison between MLN and freshly isolated mouse IEC was performed. IEC or MLN were homogenised in $1 \%$ Triton X100 in 10 mM HEPES buffered saline, pH 7.4, containing a protease inhibitor cocktail. The lysates were incubated for 30 minutes at $4^{\circ} \mathrm{C}$ and ultracentrifuged at $100000 \times g$ for one hour. Partially purified proteins were then prepared using anion exchange high pressure liquid chromatography by injecting the resultant supernatant onto a Mono-Q HR10/10 column at $\mathrm{pH} 7.8$, and by eluting the proteins from the column using a linear $0-1 \mathrm{M} \mathrm{NaCl}$ gradient. The A33 antigen (molecular weight $\sim 50 \mathrm{kDa}$ ) in eluant fractions was detected by western blot analysis using polyclonal rabbit anti-mA33antigen IgG $(1.2 \mathrm{mg} / \mathrm{ml})$. Controls to confirm the specificity of the protein detection included MLN harvested from A33 antigen deficient mice (A33-/-; Tebbutt NC, Ernst M, and Heath JK, unpublished data) and preabsorption of the anti-mA33 antigen antibodies with the immunising A33 antigen $\mathrm{C}$ terminal peptide. ${ }^{11}$ Immunohistochemical detection of the murine A33 antigen was also performed on sections of paraffin embedded MLN from normal mice using the same rabbit polyclonal antibody.
Characterisation of MODE K exosomes by western blot analysis

MODE K cells were lysed over 30 minutes at $4^{\circ} \mathrm{C}$ in $50 \mathrm{mM}$ Tris- $\mathrm{HCl}, \mathrm{pH} 8,150 \mathrm{mM} \mathrm{NaCl}, 1 \%$ EDTA, and $0.5 \%$ Triton $\mathrm{X} 100$, containing a protease inhibitor cocktail and centrifuged for 10 minutes at $700 \mathrm{~g}\left(4^{\circ} \mathrm{C}\right)$ to remove nuclei. The supernatants were ultracentrifuged for one hour at $100000 \mathrm{~g}$ $\left(4^{\circ} \mathrm{C}\right)$. Supernatants containing whole cell proteins were adjusted to $2 \mathrm{mg} / \mathrm{ml}$ in phosphate buffered saline (PBS), diluted $(1 / 2)$ in sample buffer $(2 \times)$, and stored at $-20^{\circ} \mathrm{C}$.

Exosomal proteins were separated by sodium dodecyl sulphate-polyacrylamide gel electrophoresis (SDS-PAGE) in $10 \%$ acrylamide gels. Gels were transferred onto nitrocellulose membranes (Amersham Pharmacia Biotech, Amersham Biosciences Europe, Saclay, France) in $10 \mathrm{mM}$ Tris, $0.2 \mathrm{M}$ glycine, and 30\% methanol. Non-specific binding sites were blocked by incubation in Tris-HCl, $\mathrm{pH} 7.6$, containing 5\% bovine serum albumin and $0.1 \%$ Tween. Blots were incubated for one hour with mouse anti-I-A (mouse/rat) antibodies (clone MRC OX-6; Serotec Cergy-St Christophe, France) to detect MHC class II molecules and with peroxidase conjugated sheep antimouse Ig (Amersham) (1:20 000).

A33 antigen was detected with polyclonal rabbit antimouse A33 antigen antibodies in non-reducing conditions. ${ }^{11}$ These antibodies were detected using peroxidase conjugated goat antirabbit IgG (Biorad Ivry sur Seine, France) (1:15 000), followed by ECL (Amersham Pharmacia Biotech).

MODE K derived exosomes: peptide mapping analysis using matrix assisted laser desorption ionisation-time of flight-mass spectrometry (MALDI-TOF-MS)

Identification of proteins present in MODE $\mathrm{K}$ derived exosomes was analysed using MALDI-TOF-MS. MODE K derived exosomes $(20 \mu \mathrm{g})$, prepared in sample buffer, were run on 10\% SDS-PAGE and stained with Coomassie blue. The major bands were excised from the gel and in-gel digested with trypsin. The digest solution was analysed by MALDITOF-MS using a Bruker Biflex mass spectrometer (BrukerFranzen Analytik Bremen, Germany), as previously described. ${ }^{17}$ Monoisotopic peptide masses were assigned and used in database searches. Typical search parameters, using the Microsoft FIT program, were as follows: maximum allowed peptide mass error of $100 \mathrm{ppm}$; consideration of one incomplete cleavage per peptide; no restriction was placed on the isoelectric point of the protein; and a protein mass range of 0-200 kDa was allowed.

\section{In vivo studies in mice}

We tested the capacity of MODE K epithelial exosomes to induce specific tolerance or sensitisation in mice.

Oral tolerance (humoral response)

Fifty two $\mathrm{C} 3 \mathrm{H} / \mathrm{HeN}$ mice (three week old females) were divided into six experimental groups comprising 5-10 mice each.

\section{Standard oral tolerance protocol}

The first two groups comprised tolerised and sensitised mice, obtained using standard protocols of oral tolerance. OVA tolerised mice (TOL) received $20 \mathrm{mg}$ OVA in $200 \mu \mathrm{l} 0.2 \mathrm{M}$ sodium bicarbonate by intragastric gavage using a stainless steel blunt feeding needle. OVA sensitised mice (SENS) received bicarbonate alone by gastric gavage. One week later (day 8), all mice were immunised: they received a subcutaneous injection $(100 \mu \mathrm{l})$, to the base of the tail, of $25 \mu \mathrm{g}$ OVA/complete Freund's adjuvant (CFA, v/v) and a second injection $(100 \mu \mathrm{l})$ of $10 \mu \mathrm{g}$ OVA in PBS two weeks later. One week after the second injection, blood was collected for antiOVA IgG and IgE measurements. 
Induction of tolerance by epithelial exosomes

To test for the tolerogenic capacity of exosomes, four additional groups were tested in parallel with the first two groups. In these groups, OVA loaded exosomes were administered intraperitoneally with the aim of mimicking oral administration of OVA. EXO-OVA mice received, instead of OVA gavage, an intraperitoneal injection of $10 \mu \mathrm{g}$ exosomes $(100 \mu \mathrm{l})$ derived from the MODE $\mathrm{K}$ cell line cultured in the presence of OVA under basal conditions. EXO-OVA-IFN mice received an intraperitoneal injection of $10 \mu \mathrm{g}$ OVA-exosomes derived from the MODE $\mathrm{K}$ cell line cultured in the presence of OVA and $100 \mathrm{U} / \mathrm{ml}$ IFN- $\gamma$. In some experiments, hOVA was used instead of intact OVA to produce exosomes from MODE $\mathrm{K}$ cells incubated in the presence or absence of IFN- $\gamma$. Mice in these groups received an intraperitoneal injection of $10 \mu \mathrm{g}$ exosomes and are referred to as EXO-hOVA and EXO-hOVA-IFN, respectively. After one week, all mice were immunised as stated above and blood was collected for anti-OVA IgG and IgE measurements.

\section{Oral tolerance (DTH response)}

Tolerised (TOL) and sensitised (SENS) mice were given OVA or bicarbonate buffer, respectively, by gastric gavage, as described above (see humoral response section above). The other mice received intraperitoneal OVA exosomes instead of OVA by gavage: EXO-hOVA mice received an intraperitoneal injection of $10 \mu \mathrm{g}$ exosomes derived from MODE K cells fed hOVA under basal conditions and EXO-hOVA-IFN mice received an intraperitoneal injection of $10 \mu \mathrm{g}$ exosomes derived from MODE $\mathrm{K}$ cells fed hOVA in the presence of IFN- $\gamma$. After one week, all mice were injected subcutaneously (base of the tail) with $100 \mu \mathrm{g}$ OVA/CFA. Two weeks later, mice received a subcutaneous injection of $30 \mu \mathrm{l} \mathrm{OVA} \mathrm{(} 1 \mu \mathrm{g} /$ $\mu \mathrm{l})$ in the ear and ear swelling was measured as the difference in ear thickness before and 24 hours after OVA injection using a micrometre calliper (Oditest, Kröplin, Germany) to quantify the delayed type hypersensitivity (DTH) response.

\section{Sensitisation protocol (humoral response)}

To analyse whether intestinal epithelial exosomes could directly prime the immune system, mice received an intraperitoneal injection of exosomes. EXO-hOVA mice received an injection of $10 \mu \mathrm{g}$ exosomes $(100 \mu \mathrm{l})$ derived from MODE $\mathrm{K}$ cells fed hOVA in the absence of IFN- $\gamma$ whereas EXO-hOVA-IFN mice received an injection of $10 \mu \mathrm{g}$ exosomes derived from MODE $\mathrm{K}$ cells fed hOVA in the presence of IFN- $\gamma$. A control group received an intraperitoneal injection of $100 \mu \mathrm{l}$ PBS instead of exosomes. After one week, all mice groups were injected subcutaneously with $25 \mu \mathrm{g}$ OVA/CFA in $100 \mu \mathrm{l}$. One week later mice were bled and anti-OVA IgG and IgE antibody responses were measured. In another experiment, the capacity of OVA loaded epithelial exosomes and free OVA peptides to stimulate the immune system were compared: $0.2 \mu \mathrm{g}$ of pepsin/trypsin ovalbumin peptides (hOVA), calculated as being equivalent to the amount loaded on $10 \mu \mathrm{g}$ epithelial exosomes in IFN- $\gamma$ conditions, were injected intraperitoneally in order to prime the mice before the subcutaneous OVA boost.

\section{Measurement of OVA specific $\lg E$ and $\lg G$ antibodies (ELISA)}

IgG and IgE titres in plasma were measured using an enzyme linked immunosorbent assay as follows: 96 well plates (Immulon II, Labsystems, France) were coated overnight at $4^{\circ} \mathrm{C}$ with $100 \mu \mathrm{l}$ of $25 \mu \mathrm{g} / \mathrm{ml}$ OVA (Sigma) in PBS. After washes with PBS-0.05\% Tween 20 (PBS-Tween), non-specific binding sites were blocked for one hour at $37^{\circ} \mathrm{C}$ with $100 \mu \mathrm{l} /$ well of PBS-1\% bovine serum albumin. The plates were then incubated for two hours at $37^{\circ} \mathrm{C}$ with $100 \mu$ plasma samples serially diluted in PBS-Tween. Peroxidase conjugated rat antimouse IgG (Serotec) diluted 1:1000 in PBS-Tween were added $(100 \mu \mathrm{l} /$ well $)$ and incubated for two hours at $37^{\circ} \mathrm{C}$. Finally, $100 \mu \mathrm{l}$ of citrate buffer, $\mathrm{pH} 4.0$, containing $10 \mathrm{mg}$ ortho-phenylenediamine (Sigma) and $\mathrm{H}_{2} \mathrm{O}_{2}$ (Sigma) were added to each well. The reaction was stopped with $50 \mu \mathrm{l} /$ well $6 \mathrm{~N} \mathrm{H}_{2} \mathrm{SO}_{4}$ and plates were read at $450 \mathrm{~nm}$ using an automatic Multiskan microplate reader (Labsystems, Cergy-Pontoise, France).

\section{Statistical analysis}

Statistical analysis was performed using SAS software. Results are expressed as mean (SD). Comparison of means was performed using analysis of variance and non-parametric Wilcoxon tests. The general linear model procedure was also used for multiple group to group comparisons. Differences were considered significant when $\mathrm{p}<0.05$.

\section{RESULTS \\ Characterisation of MODE $\mathrm{K}$ intestinal epithelial exosomes}

Two molecules found in human epithelial exosomes, ${ }^{7}$ namely MHC class II molecules and A33 antigen, were analysed by western blot. As shown in fig 1A, MHC class II molecules were not detectable in MODE $\mathrm{K}$ cell lysates, even in the presence of IFN- $\gamma$. MHC class II molecules were detectable in MODE K derived exosomes harvested under basal conditions and their expression was markedly upregulated in the presence of IFN- $\gamma$, indicating substantial enrichment in epithelial exosomes. The discrepancy between expression of MHC class II molecules in entire cells and exosomes may be due to the antibodies differentially recognising the mature peptide bound class II molecules possibly present on exosomes compared with nascent class II forms mainly present in epithelial cells. A33 antigen was detected in cell lysates and was highly enriched in exosomes although its expression in exosomes was not upregulated by IFN- $\gamma$ (data not shown).
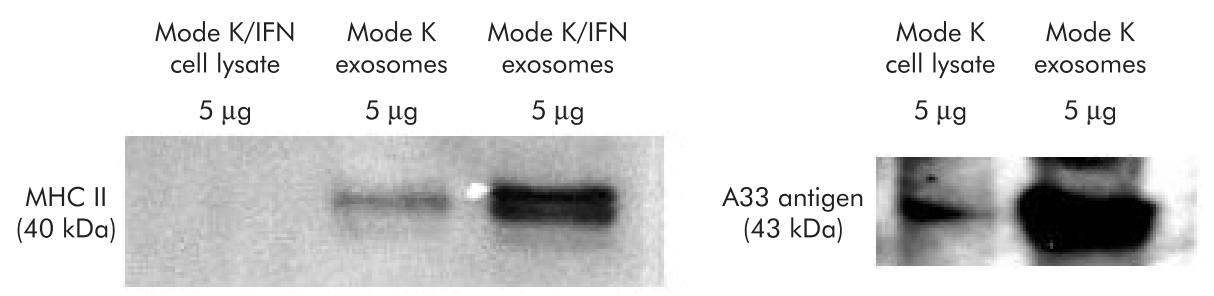

Figure 1 Expression of major histocompatibility complex (MHC) class II molecules and A33 antigen in MODE K cells incubated in the presence or absence of interferon $\gamma($ IFN- $\gamma$ ), and in MODE K cell derived exosomes. Although MODE K cell lysates did not express detectable levels of MHC class II molecules, even in the presence of IFN- $\gamma$, MODE K derived exosomes expressed detectable levels under basal conditions, which were markedly upregulated in the presence of IFN- $\gamma$. A33 antigen, a molecule expressed specifically by intestinal epithelial cells, was enriched in exosome preparations compared with whole cell lysates. 


\section{Peptide mapping by MALDI-TOF-MS analysis}

The results of peptide mapping of MODE K derived exosomes are summarised in table 1. Several protein families were observed: (a) proteins playing a role in the biogenesis and release of exosomes, such as integrin precursors and cytoskeleton proteins under basal and inflammatory (+IFN- $\gamma$ ) conditions and Ras related protein (Rab-2, Rab-7); (b) proteins responsible for directing exosomes to their target cells, such as MFG-E8, a protein previously found in dendritic cell derived exosomes, ${ }^{18}$ and heat shock proteins hsp7l and hsp90 that may play a role in the transfer of antigenic peptides and binding to dendritic cells, and in their maturation, as recently described in mast cell derived exosomes $^{19}$; (c) proteins potentially involved in antigen presentation (MHC class I molecules) or in exosome function (tetraspan molecules CD81, CD82, and undescribed transmembrane four superfamily protein); and (d) cytoplasmic proteins probably not related to exosome function which may have been non-specifically captured into the exosome lumen during their formation (histones, enzymes).

\section{Epithelial exosomes do not induce tolerance in mice} Humoral tolerance

An earlier study suggested that epithelium derived exosomes might induce oral tolerance in rats. ${ }^{15}$ In contrast, in our murine model, MODE $\mathrm{K}$ derived exosomes bearing MHC class II/OVA molecules and injected intraperitoneally did not suppress IgE and IgG antibody responses (fig 2A, B). As expected, anti-OVA antibodies were significantly lower in tolerised (TOL) mice (60 and 3950 for IgE and IgG titres, respectively) than in sensitised (SENS) (480 and 192 000, for IgE and IgG titres; $\mathrm{p}<0.001)$ mice, but Ig titres observed in EXO-OVA or EXO-OVA-IFN mice were not significantly different from those observed in SENS mice, indicating that epithelial exosomes did not tolerise mice to OVA. Furthermore, anti-OVA antibody titres were significantly higher in EXO-hOVA-IFN mice than in SENS mice (IgE $6.15 \times 10^{3} \quad v \quad 0.48 \times 10^{3} \quad(\mathrm{p}<0.0001)$; and $\operatorname{IgG} 900 \times 10^{3} v$ $\left.192 \times 10^{3}(\mathrm{p}<0.0001)\right)$, suggesting that exosomes may sensitise rather than tolerise mice, at least in our experimental conditions.

Table 1 Peptide mapping of MODE K derived epithelial exosomes using matrix assisted laser desorption ionisation-time of flight-mass spectrometry (MALDI-TOF-MS) analysis

\begin{tabular}{|c|c|c|c|c|}
\hline Band No & $\begin{array}{l}\text { Proteins identified from MODE K } \\
\text { derived exosomes }\end{array}$ & $\begin{array}{l}\text { Molecular } \\
\text { mass (kDa) }\end{array}$ & $\begin{array}{l}\text { Proteins identified from MODE K+IFN- } \gamma \\
\text { derived exosomes }\end{array}$ & $\begin{array}{l}\text { Molecular mass } \\
\text { (kDa) }\end{array}$ \\
\hline \multirow[t]{7}{*}{ Band M-1 } & & & A-X actin ,Q61276 & 41.7 \\
\hline & & & Clathrin heavy chain P1 1442 & 193.2 \\
\hline & & & $\begin{array}{l}\text { Similar to ubiquitin C P11276 } \\
\text { Q92278 65.5kD }\end{array}$ & 273.3 \\
\hline & & & Fibronectin precursor P1 1276 & 273.3 \\
\hline & & & Heat shock protein HSP 90-alpha P07901 & 85.5 \\
\hline & Heat shock protein HSP 71 kD P08109 & 71 & Heat shock protein HSP 71 kD P08109 & 71 \\
\hline & Heat shock protein HSP 90-beta protein P34058 & & Heat shock protein HSP 90-beta protein P34058 & 85.5 \\
\hline Band $M-2$ & & & Similar to ubiquitin C, Q922Z8 & 65.5 \\
\hline \multirow{2}{*}{ Band $M-3$} & Integrin beta-1 precursor, P09055 & 91.7 & Integrin beta-1 precursor, P09055 & 91.7 \\
\hline & & & Integrin alpha-3 precursor, Q62470 & 117.8 \\
\hline Band $M-4$ & $\begin{array}{l}\text { Prostaglandin F2-alpha receptor regulatory protein, } \\
\text { Q9WV91 }\end{array}$ & 99.6 & $\begin{array}{l}\text { Prostaglandin F2-alpha receptor regulatory protein, } \\
\text { Q9WV91 }\end{array}$ & 99.6 \\
\hline Band $M-5$ & Serine protease HTRA1 precursor, Q9R118 & 51.2 & Moesin, P26041 & 67.6 \\
\hline Band $M-6$ & & & Moesin, P26041 & 67.6 \\
\hline Band $M-7$ & & & EH-domain containing protein 1, Q9WVK4 & 60.6 \\
\hline Band $M-8$ & & & Pyruvate kinase, M2 isozyme, P52480 & 57.7 \\
\hline \multirow[t]{3}{*}{ Band M-9 } & $\begin{array}{l}22 \text { kDa Neuronal tissue-enriched acidic protein., } \\
\text { Q91XV3 }\end{array}$ & 22.2 & $\begin{array}{l}22 \text { kDa Neuronal tissue enriched acidic protein, } \\
\text { Q91XV3 }\end{array}$ & 22.2 \\
\hline & & & Pyruvate kinase, P52480 & 57.7 \\
\hline & CD82 antigen, P40237 & 29.6 & CD82 antigen, P40237 & 29.6 \\
\hline \multirow{2}{*}{ Band $M-10$} & Milk fat globule glycoprotein MFG-E8 S & 48.8 & Alpha Enolase, P17182 & 47.3 \\
\hline & Calpactin I light chain, P08207 & 11.1 & Annexin II, P07356 & 38.8 \\
\hline \multirow[t]{2}{*}{ Band $M-11$} & Annexin I P10107 & 38.8 & H-2 class I histocompatibility antigen, $\mathrm{P0} 4223$ & 41.6 \\
\hline & Kératine P02535 & 57.8 & & \\
\hline \multirow{2}{*}{ Band $M-12$} & & & Annexin A4 (Annexin IV), P97429 & 36.1 \\
\hline & & & Annexin I (Lipocortin I) P10107 & 38.8 \\
\hline \multirow[t]{2}{*}{ Band $M-13$} & & & Transmembrane 4 superfamily, Q64302 & 23.1 \\
\hline & & & Annexin I, P10107 & 38.8 \\
\hline \multirow{6}{*}{ Band M-14 } & Annexin V, P48036 & 35.7 & CD9 antigen, P40240 & 25.0 \\
\hline & Annexin I, P10107 & 38.5 & CD81 antigen, P35762 & 25.8 \\
\hline & Annexin A4, P97429 & 35,8 & & \\
\hline & Histone H1.3, P15864 & 22.2 & & \\
\hline & Histone H1.5, P43276 & 22.4 & & \\
\hline & Histone H1.4, P43274 & 21.8 & & \\
\hline \multirow{2}{*}{ Band M-15 } & Annexin A4, P97429 & 35.8 & & \\
\hline & Annexin I, P10107 & 38.7 & & \\
\hline \multirow[t]{2}{*}{ Band M-16 } & Histone H3, P02301 & 14.9 & 14-3-3 protein zeta/delta, P35215 & 27.7 \\
\hline & Histone H1.1,P15864 & 21.1 & & \\
\hline \multirow{4}{*}{ Band M-17 } & & & Ferritin light chain 1, P29391 & 20.6 \\
\hline & & & Ras related protein Rab-2, P53994 & 23.5 \\
\hline & & & Ras related protein Rab-7, P51150 & 23.5 \\
\hline & & & Myeloid associated differentiation marker, $\mathrm{O} 35682$ & 32.08 \\
\hline Band $M-18$ & & & Histone H1.3 , P43277 & 21.9 \\
\hline \multirow{2}{*}{ Band M-19 } & & & Histone H2B F, P10853 & 13.8 \\
\hline & & & Ferritin heavy chain, P09528 & 21.0 \\
\hline
\end{tabular}

MODE K derived exosomes $(20 \mu \mathrm{g})$ were run on $10 \%$ sodium dodecyl sulphate-polyacrylamide gel electrophoresis and stained with Coomassie blue. The major bands were excised from the gel and in-gel digested with trypsin. The digest solution was analysed by MALDI-TOF-MS.

IFN- $\gamma$, interferon $\gamma$. 


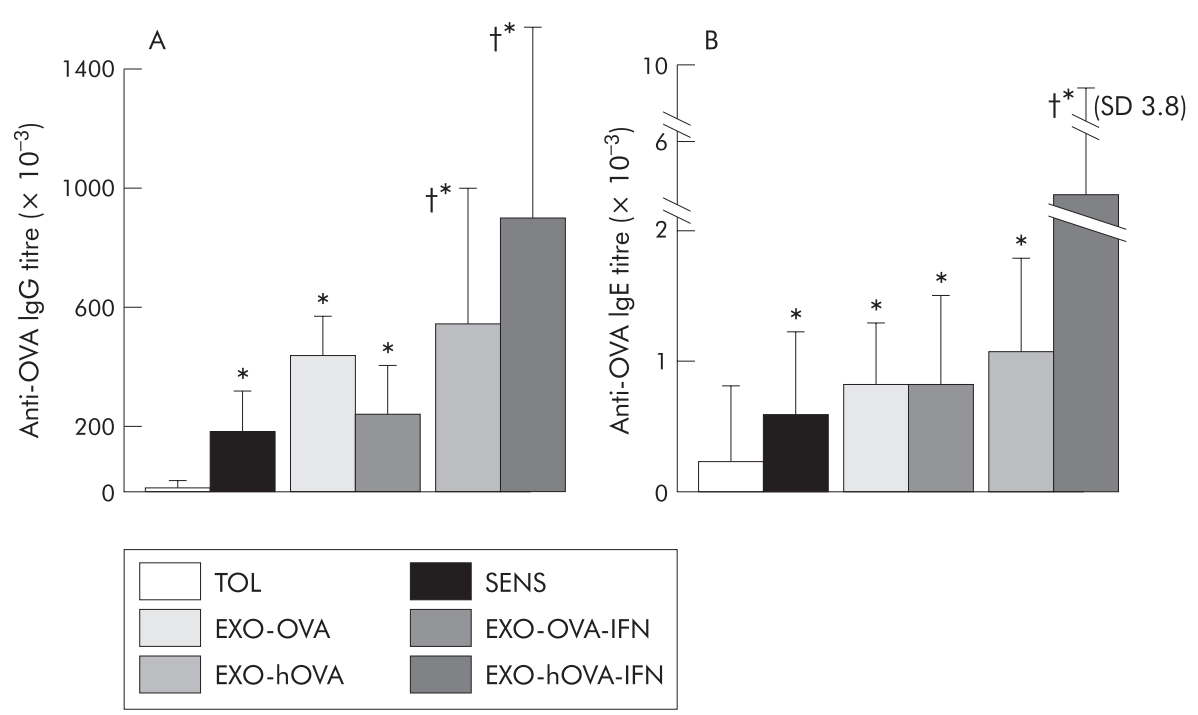

Figure 2 Ovalbumin (OVA) loaded epithelial exosomes, injected intraperitoneally, did not abrogate humoral immune responses. Anti-OVA IgG and IgE titres obtained in $\mathrm{C} 3 \mathrm{H} / \mathrm{HeN}$ mice were orally tolerised to OVA (TOL), OVA sensitised (SENS), or injected intraperitoneally with exosomes derived from MODE K cells fed intact OVA (EXO-OVA) or pepsin-trypsin hydrolysed OVA (EXO-hOVA), or from MODE K cells treated with interferon $\gamma$ (IFN- $\gamma$ ) (EXO-OVA-IFN and EXO-hOVA-IFN). Not only did exosomes not induce specific humoral tolerance, but on the contrary, EXO-OVAh-IFN and EXOOVA increased sensitisation to OVA. ${ }^{*} p<0.05$ compared with tolerised mice; $\uparrow p<0.03$ compared with sensitised mice $(n=5-16$ mice per group).

\section{DTH tolerance}

As shown in fig 3, the cellular response (DTH) was decreased in orally tolerised mice compared with sensitised mice ( $28 \mathrm{v}$ $89 \mu \mathrm{m} ; \mathrm{p}<0.05$ ) as expected, but not in mice that received $10 \mu \mathrm{g}$ EXO-hOVA or EXO-hOVA-IFN by intraperitoneal injection (89 and $98 \mu \mathrm{m}$, respectively), indicating that epithelial exosomes administered intraperitoneally did not tolerise the cellular immune response to OVA.

\section{Epithelial exosomes can prime mouse humoral responses}

IEC derived exosomes, under our experimental conditions, were unable to induce tolerisation of mice towards OVA and even seemed to enhance the sensitisation process. As shown in fig 4, exosomes derived from MODE $\mathrm{K}$ cells stimulated by

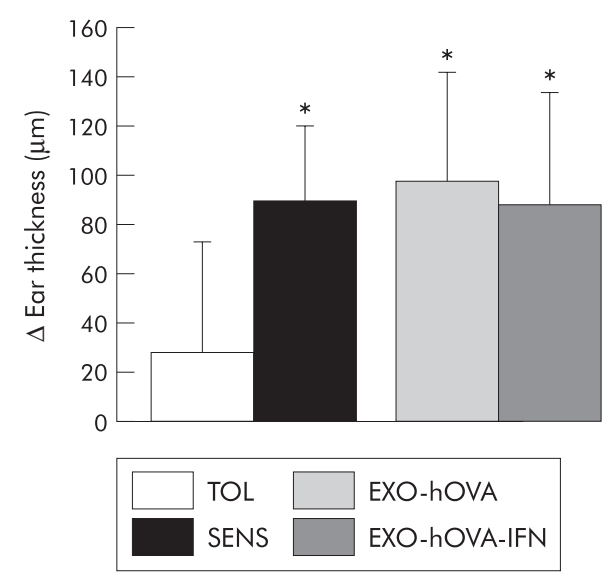

Figure 3 Ovalbumin (OVA) loaded epithelial exosomes injected intraperitoneally did not abrogate the cellular immune response (delayed type hypersensitivity), as measured by the difference in ear thickness before and after local injection of OVA or pepsin-trypsin hydrolysed OVA (EXO-hOVA), or from MODE K cells treated with interferon $\gamma$ (IFN- $\gamma$ ) (EXO-hOVA-IFN). * ${ }^{*}<0.05$ compared with tolerised (TOL) mice ( $n=5-8$ mice per group). SENS, sensitised mice.
IFN- $\gamma$ in the presence of hOVA (EXO-hOVA-IFN) primed a specific anti-OVA humoral immune response. This response was not observed with exosomes prepared in the absence of IFN- $\gamma$ (EXO-hOVA) that express fewer or non-functional MHC class II/OVA peptide complexes. These results suggest that IFN- promotes the release of functional epithelial exosomes bearing MHC II/OVA-peptide complexes able to stimulate the immune system. In addition, immunisation of mice with $0.2 \mu \mathrm{g}$ of OVA peptides (calculated as being equivalent to the amount expressed on $10 \mu \mathrm{g}$ epithelial exosomes under IFN- $\gamma$ conditions), with or without CFA, did not induce a significant IgG response. This result highlighted the increased efficiency of peptide loaded epithelial exosomes in stimulating the immune system compared with free peptides.

\section{Mouse epithelial exosomes are present in mesenteric lymph nodes but not in serum}

As IEC derived exosomes seem to act as vehicles of the antigenic information originating from the gut lumen, we searched for their presence in mice MLN. We used A33 antigen as a specific marker of epithelial exosomes to detect their presence in the lymph nodes draining the small intestine. As shown in fig 5A, MLN lysates contained A33 antigen, suggesting the presence of IEC derived exosomes in these secondary lymphoid organs. The amount of A33 antigen detected in MLN was much lower than that observed using lysates from purified IEC. The A33 antigen band was specific, as preabsorption of the immune serum with A33 antigen immunising peptide led to the disappearance of the band, and A33-/- mice did not display any specific bands. An immunohistochemical study of the localisation of A33 antigen in MLN (fig 5B) suggested that A33 antigen was enriched on the external membranes of immune cells entering the MLN in the subcapsular sinus. However, on a cautionary note, while the presence of A33 antigen in MLN might be a reliable indicator of the presence of epithelial exosomes, an alternative explanation would be that the A33 antigen was present as a result of a subpopulation of dendritic cells transporting apoptotic intestinal epithelial cells in phagocytic vacuoles to T cell areas of MLN. ${ }^{20}$ The apparent distribution of A33 antigen on the external 


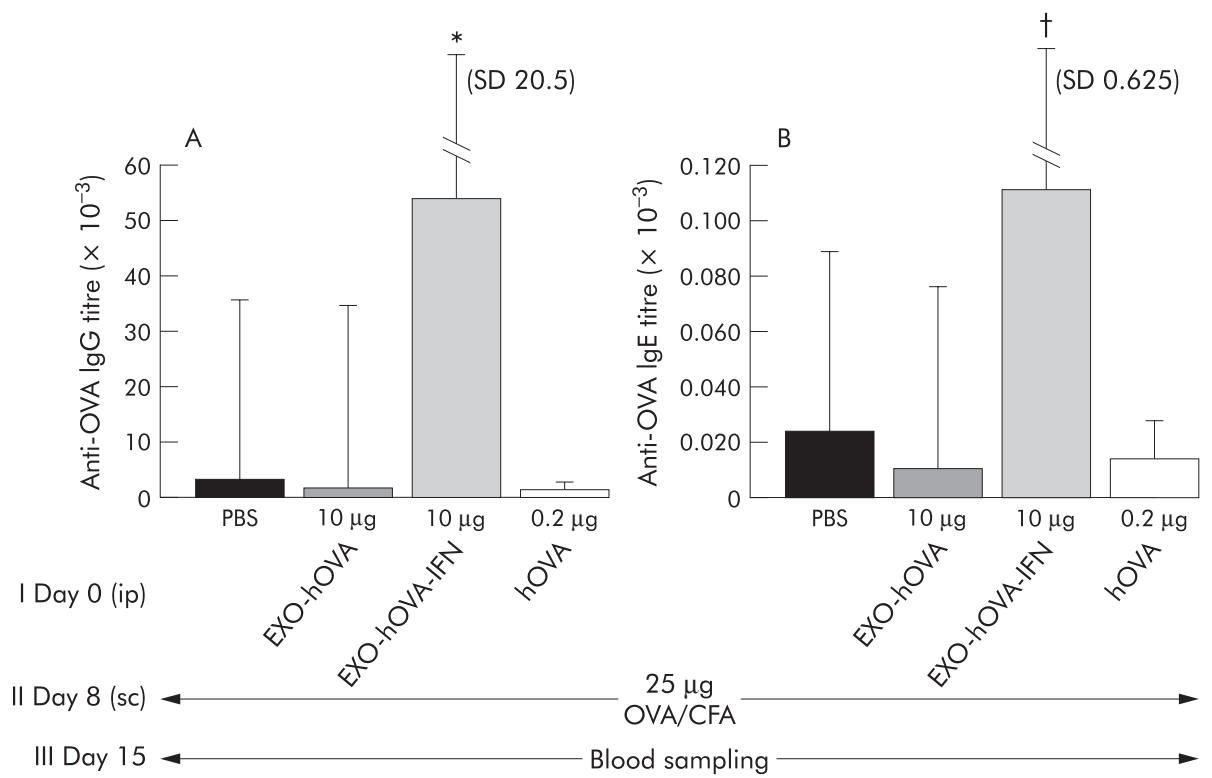

Figure 4 Epithelial exosomes can prime the humoral immune response in mice. Anti- ovalbumin (OVA) lgG and lgE titres obtained in $\mathrm{C} 3 \mathrm{H} / \mathrm{HeN}$ mice injected intraperitoneally (ip) with phosphate buffered saline (PBS) or exosomes obtained from MODE K cells exposed to pepsin-trypsin OVA hydrolysate (hOVA) and incubated in the presence or absence of interferon $\gamma$ (IFN- $\gamma$ ) (EXO-hOVA and EXO-hOVA-IFN) before subcutaneous (sc) injection of OVA/complete Freund's adjuvant (CFA). Exosomes obtained in the presence of IFN- $\gamma$ (thus bearing more MHC II/OVA peptide complexes) were capable of inducing specific $\lg G$ and $\lg E$ responses. The amount of hOVA peptides corresponding to that loaded on $10 \mu \mathrm{g}$ EXO/hOVA/IFN (that is, $0.2 \mu \mathrm{g}$ ) did not induce an $\mathrm{lg} G$ response, even in the presence of CFA. IgE responses to $0.2 \mu \mathrm{g}$ OVA peptides did not parallel lgG responses, suggesting differential susceptibilities to low dose antigens ( $n=4-9$ mice per group). ${ }^{*} p<0.001$ compared with the other groups; †compared with EXO-hOVA $(p<0.02)$, PBS $(p<0.08)$, and hOVA $(p<0.02)$.

membranes of the immune cells in the MLN (rather than in apoptotic bodies) would tend to argue against this possibility.

We also searched for the presence of intestinal epithelial exosomes at the systemic level by analysing human and mice serum derived exosomes for their content in A33 antigen. We were unable to detect significant amounts of A33 antigen in serum derived exosomes (data not shown) suggesting that free intestinal epithelial exosomes do not achieve significant concentrations in the circulation.

\section{DISCUSSION}

The present results show that murine IEC stimulated with IFN- $\gamma$ in vitro release exosomes bearing MHC class II

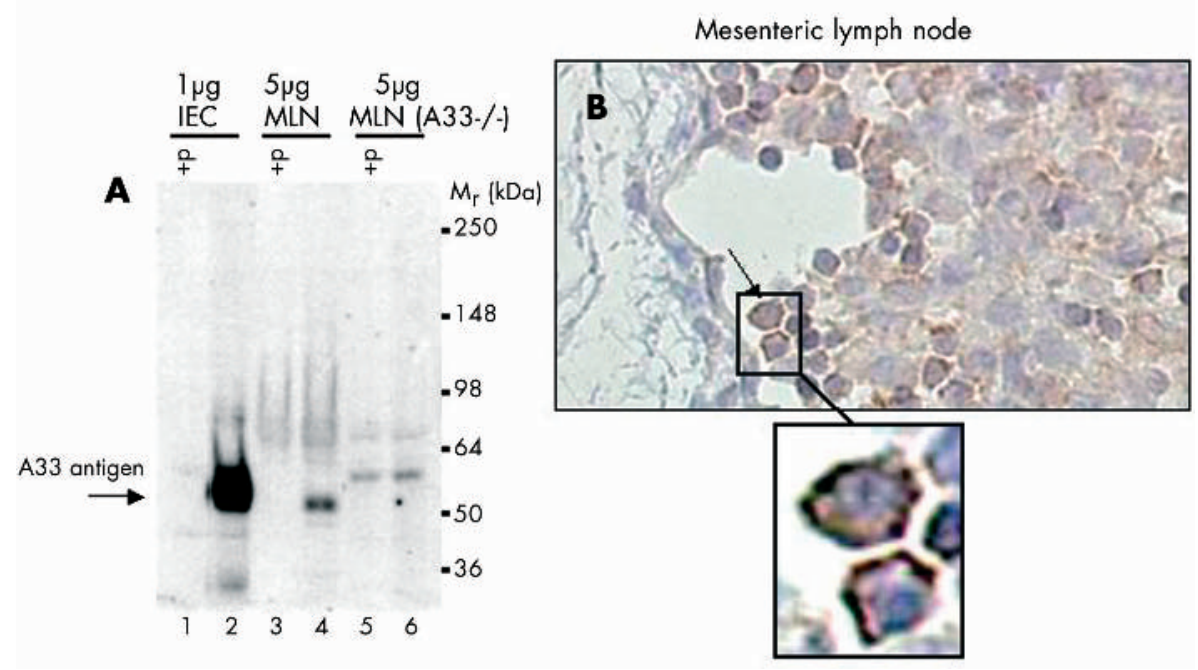

Figure 5 (A) Western blot analysis of A33 antigen in mice mesenteric lymph node (MLN) lysates showing significant expression of A33 antigen and suggesting that $\mathrm{A} 33$ antigen, a marker of intestinal epithelial cells (IEC), also expressed in exosomes, can reach the draining lymph nodes. The western blot was performed under reducing conditions using a rabbit polyclonal anti-mA33 antigen $\operatorname{lgG}(1.2 \mathrm{mg} / \mathrm{ml})$. Proteins were extracted from mouse IEC $(1 \mu \mathrm{g}$ protein: lanes 1 and 2), MLN (5 $\mu$ g protein: lanes 3 and 4), and MLN from A33 antigen deficient mice (A33- / - ) (5 $\mu \mathrm{g}$ protein: lanes 5 and 6$)$. In lanes 1, 3, and 5, the analysis was conducted after preabsorption of the anti-mA33 antigen $\mathrm{lgG}$ with $0.75 \mathrm{mg} / \mathrm{ml}(\sim 50 \times \mathrm{molar}$ excess) of the immunising mA33 antigen peptide (+P). (B) Immunohistochemistal analysis of MLN from C3H/HeN mice, showing immune cells entering the subcapsular sinus and displaying the A33 antigen at their surface (see magnified inset), suggesting that epithelial exosomes may reach MLN via migration of antigen presenting cells. It cannot be excluded however that the A33 antigen immunoreactivity is due to the presence of intestinal epithelial apoptotic bodies, although enrichment of the staining around the periphery of the cells argues against this explanation. 


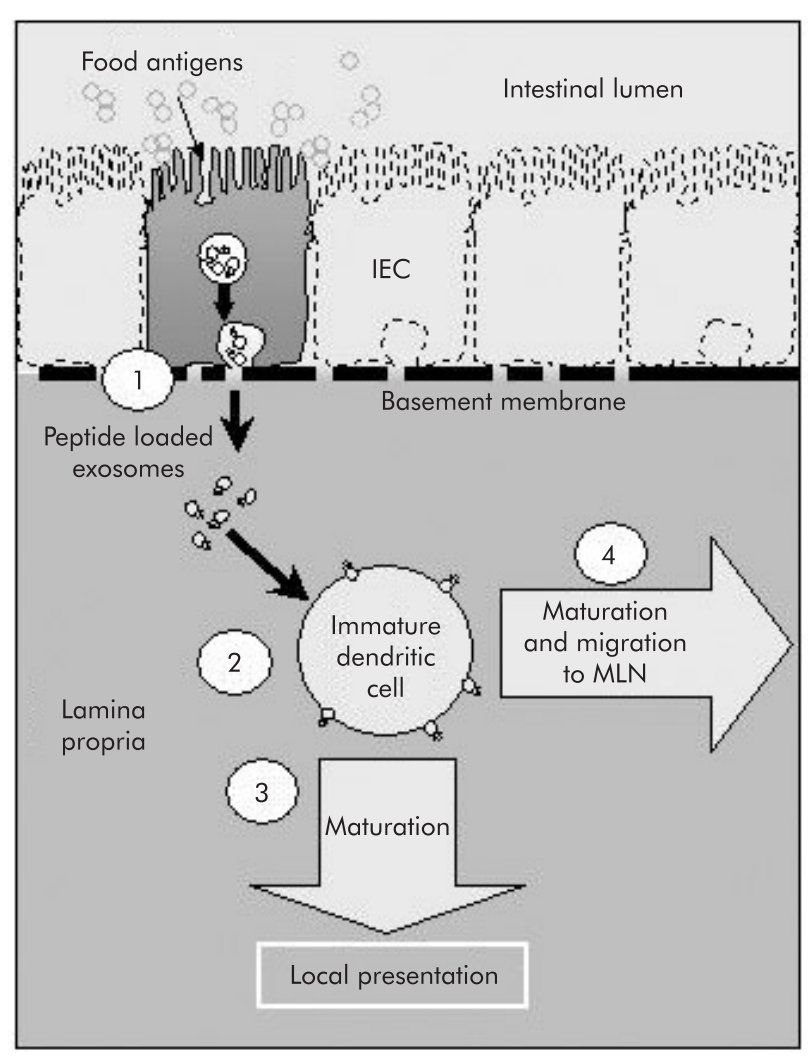

Figure 6 Working hypothesis on the role of epithelial derived exosomes. Exosomes released at the basolateral surfaces of enterocytes and loaded with luminal antigen derived peptides cross the basement membrane to reach the lamina propria (1) where they may interact with dendritic cells (DCs) (2). After maturation of exosome loaded DCs, antigen presentation may take place locally (3), or epithelial exosomes/ DCs may migrate to the draining lymph nodes (4). IEC, intestinal epithelial cells; MLN, mesenteric lymph nodes.

molecules/peptide complexes that, when administered intraperitoneally to mice, induce a specific immune response.

The murine intestinal epithelial cell line MODE $\mathrm{K}^{16}$ produced exosomes displaying a pattern of molecule expression similar to that previously described in human intestinal epithelial exosomes, suggesting that these molecules play an important role in exosome biogenesis and function. The presence of the tetraspan proteins CD9, CD81, and CD82 confirms their endosomal origin and MHC class II molecules, upregulated by IFN- $\gamma$, underline their potential to carry dietary protein derived peptides. The heat shock proteins hsp7l and hsp90 could play a role in the transfer of peptides from IEC to professional APC. Indeed, hsps have been involved in peptide exchange with MHC class II molecules after internalisation of hsp-peptide complexes through the CD91 receptor present on APC, and their role in cross presentation by dendritic cells of antigen associated exosomes from mast cells has recently been described. ${ }^{19}$ Hsps may also induce maturation and migration of dendritic cells to the draining lymph nodes. ${ }^{21}$ Epithelial exosomes were also shown to bear A33 antigen, a molecule that is highly specific for intestinal epithelial cells, and MFG-E8,22 23 a molecule that binds to dendritic cell integrins that could play a role in adhesion of exosomes to their target cell. It is noteworthy that no costimulatory molecules were found on epithelial exosomes.

In the present study, we tried to reproduce the array of OVA peptides produced in the digestive tract in vivo by mimicking gastric and pancreatic hydrolysis by pepsin and trypsin. The resulting OVA peptides were placed in contact with the intestinal epithelial cell line, MODE $\mathrm{K}$, allowing further uptake and processing of OVA peptides by IEC prior to their loading on MHC class II molecules, especially in the presence of IFN- $\gamma$. It is generally accepted that antigen presentation at the intestinal level is tolerogenic, at least under basal conditions. ${ }^{13}{ }^{24}$ In the present study, OVA loaded MODE K exosomes were used in a tolerisation protocol, in order to check whether their intraperitoneal administration could mimic the tolerising effect induced by an oral dose of OVA. In contrast with results previously reported on epithelial tolerosomes, ${ }^{15}$ intraperitoneal injection of OVA loaded epithelial exosomes in mice did not induce a tolerogenic humoral or cellular immune response to OVA. The fact that EXO-OVA-IFN and EXO-hOVA-IFN generated different responses (hOVA having greater potential to sensitise mice) suggests that processing of food antigens by epithelial cells may lead to the formation of distinct peptide epitopes.

The discrepancy between our results and those previously reported on epithelial tolerosomes ${ }^{15}$ is difficult to explain although the two studies were conducted using different epithelial cell lines and different animal models.

As we did not observe any tolerogenic effect of epithelial exosomes delivered through the intraperitoneal route, we tested whether they might, per se, induce a specific immune response to OVA. We found that MODE $\mathrm{K}$ derived exosomes loaded with OVA peptides in the presence of IFN- $\gamma$ were capable of inducing a strong OVA specific immune response when administered intraperitoneally. The absence of response with OVA exosomes obtained in the absence of IFN $-\gamma$ suggested that a certain density of MHC class II molecules on the exosomal surface is mandatory to the immune response. Alternatively, MHC class II molecules present on exosomes in the absence of IFN- $\gamma$ have been described as nascent rather than mature MHC class II forms ${ }^{25}$; these immature nascent forms have been suggested to induce tolerogenic rather than immunogenic responses.

Our results indicate that epithelial exosomes can induce a significant immune response to OVA despite their lack of costimulatory molecules. This would indicate that they would most probably have to interact with professional APC expressing these molecules in order to induce an immune response, as previously demonstrated with dendritic cell derived exosomes. ${ }^{14}$ Indeed, our results are in agreement with those recently reported in mice on dendritic cell derived exosomes which, after injection, can generate an antigen specific MHC class II restricted $\mathrm{CD}^{+} \mathrm{T}$ cell proliferation and upregulation of activation markers. This activation mainly depends on costimulatory molecules expressed by dendritic cells, and not those present on exosomes. ${ }^{14}$ In the same way, mast cell derived exosomes also need dendritic cells to efficiently activate $\mathrm{T}$ cells in vitro, ${ }^{26}$ suggesting that MHC class II-peptide complexes are transferred from exosomes to dendritic cells. The interactions between APC and exosomes was also demonstrated with B cell derived exosomes which were shown to bind specifically to follicular dendritic cells in germinal centres. ${ }^{27}$ In our study, intestinal epithelial exosomes also seem to play a role as MHC/peptide carriers. We artificially injected these epithelial exosomes intraperitoneally, which is not the site (intestinal mucosa) where they are released normally. We hypothesise (fig 6) that epithelial exosomes may allow the luminal antigens taken up and processed by epithelial cells to be transferred from the intestinal lumen, via epithelial exosomes, to the local intestinal dendritic cells "sensing" the content of the gut lumen, and to the MLN. Indeed, A33 antigen, a specific marker of epithelial cells ${ }^{11}$ highly enriched on epithelial exosomes, was detected in lysates from MLN. This antigen 
sampling pathway via exosomes could add to the previously described direct sampling, by dendritic cells, of bacteria present in the intestinal lumen, through the epithelial tight junctions. ${ }^{28}$ In the intestinal suppressive environment (transforming growth factor $\beta$ ), the immune recognition of exosome derived peptides by mucosal lymphocyte populations, either directly (without costimulation) or indirectly through professional APC, might drive a tolerogenic response in the gut, the "natural" environment for exosomes, at least under physiological conditions. Thus effector cells that interact with exosome derived epitopes, together with the microenvironment in which this occurs, are probably key factors in determining the outcome of the immune response, the same determinants triggering different responses within different sites. In infectious conditions, maturation of dendritic cells in the presence of "danger signals" (lipopolysaccharide, TNF- $\alpha$ ), ${ }^{29}$ as well as the increase in MHC class II/peptide density on epithelial exosomes, may explain an abnormal immune response to luminal antigens. This hypothesis requires further investigation.

In summary, our results suggest that epithelial exosomes may serve as messengers sensing the antigenic content of the gut lumen. Transmission of immune information via epithelial exosomes to professional APC present in the intestinal mucosa may be one of the pathways involved in the immune response to intestinally delivered antigens.

\section{ACKNOWLEDGMENTS}

$G$ van Niel was a recipient of a grant from the Fondation pour la Recherche Médicale.

\section{Authors' affiliations}

G Van Niel, J Mallegol, C Bevilacqua*, C Candalh, N Cerf-Bensussan, M Heyman, INSERM EMI 0212, Faculté Necker-Enfants Malades, 156 rue de Vaugirard, Paris, France

S Brugière, CEA, Laboratoire de Chimie des Protéines, Grenoble, France E Tomaskovic-Crook, J K Heath, Ludwig Institute for Cancer Research, Post Office Royal Melbourne Hospital, Parkville, Victoria 3050, Australia

*J Mallegol and C Bevilacqua contributed equally to this work

\section{REFERENCES}

1 Terpend K, Boisgerault F, Blaton MA, et al. Protein transport and processing by human HT29-19A intestinal cells: effect of interferon gamma. Gut 1998:42:538-45.

2 Hershberg RM, Framson PE, Cho DH, et al. Intestinal epithelial cells use two distinct pathways for HLA class II antigen processing. J Clin Invest 1997; 100:204-15.

3 Kaiserlian D, Vidal K, Revillard JP. Murine enterocytes can present soluble antigen to specific class II-restricted CD4+ T cells. Eur J Immunol 1989; 19:1513-16.

4 Hershberg RM, Cho DH, Youakim A, et al. Highly polarized HLA class II antigen processing and presentation by human intestinal epithelial cells. J Clin Invest 1998;102:792-803.
5 Framson $\mathrm{PE}$, Cho $\mathrm{DH}$, Lee $\mathrm{LY}$, et al. Polarized expression and function of the costimulatory molecule CD58 on human intestinal epithelial cells. Gastroenterology 1999;116:1054-62.

6 Kvale D, Krajci P, Brandtzaeg P. Expression and regulation of adhesion molecules ICAM-1 (CD54) and LFA-3 (CD58) in human intestinal epithelial cell lines. Scand J Immunol 1992;35:669-76.

7 van Niel G, Raposo G, Candalh C, et al. Intestinal epithelial cells secrete exosome-like vesicles. Gastroenterology 2001;121:337-49.

8 Raposo G, Niiman HW, Stoorvogel W, et al. B lymphocytes secrete antigenpresenting vesicles. J Exp Med 1996;183:1161-72.

9 Zitvogel L, Regnault A, Lozier A, et al. Eradication of established murine tumors using a novel cell-free vaccine: dendritic cell-derived exosomes. Nat Med 1998;4:594-600.

10 Heath JK, White SJ, Johnstone CN, et al. The human A33 antigen is a transmembrane glycoprotein and a novel member of the immunoglobulin superfamily. Proc Natl Acad Sci U S A 1997;94:469-74.

11 Johnstone CN, Tebbutt NC, Abud HE, et al. Characterization of mouse A33 antigen, a definitive marker for basolateral surfaces of intestinal epithelial cells. Am J Physiol Gastrointest Liver Physiol 2000;279:G500-10.

12 Wolfers J, Lozier A, Raposo G, et al. Tumor-derived exosomes are a source of shared tumor rejection antigens for CTL cross-priming. Nat Med 2001;7:297-303.

13 Hanson DG, Vaz NM, Maia LC, et al. Inhibition of specific immune responses by feeding protein antigens. Int Arch Allergy Appl Immunol 1977;55:526-32.

14 Thery C, Duban L, Segura E, et al. Indirect activation of naive CD4+ T cells by dendritic cell-derived exosomes. Nat Immunol 2002;3:1156-62.

15 Karlsson M, Lundin S, Dahlgren U, et al. "Tolerosomes" are produced by intestinal epithelial cells. Eur J Immunol 2001;31:2892-900.

16 Vidal K, Grosjean I, Evillard JP, et al. Immortalization of mouse intestinal epithelial cells by the SV40-large T gene. Phenotypic and immune characterization of the MODE-K cell line. J Immunol Methods 1993:166:63-73.

17 Rabilloud T, Kieffer S, Procaccio V, et al. Two-dimensional electrophoresis of human placental mitochondria and protein identification by mass spectrometry: toward a human mitochondrial proteome. Electrophoresis 1998; 19:1006-14

18 Thery C, Regnault A, Garin J, et al. Molecular characterization of dendritic cell-derived exosomes. Selective accumulation of the heat shock protein hsc73. J Cell Biol 1999;147:599-610.

19 Skokos D, Botros HG, Demeure C, et al. Mast cell-derived exosomes induce phenotypic and functional maturation of dendritic cells and elicit specific immune responses in vivo. J Immunol 2003:170:3037-45.

20 Huang FP, Platt N, Wykes M, et al. A discrete subpopulation of dendritic cells transports apoptotic intestinal epithelial cells to T cell areas of mesenteric lymph nodes. J Exp Med 2000;191:435-44.

21 Srivastava $\mathbf{P}$. Roles of heat-shock proteins in innate and adaptive immunity. Nat Rev Immunol 2002;2:185-94.

22 Andersen MH, Berglund L, Rasmussen JT, et al. Bovine PAS- $6 / 7$ binds alpha v beta 5 integrins and anionic phospholipids through two domains. Biochemistry 1997;36:5441-6.

23 Taylor MR, Couto JR, Scallan CD, et al. Lactadherin (formerly BA46), a membrane-associated glycoprotein expressed in human milk and breast carcinomas, promotes Arg-Gly-Asp (RGD)-dependent cell adhesion. DNA Cell Biol 1997; 16:861-9.

24 Nagler-Anderson C, Shi HN. Peripheral nonresponsiveness to orally administered soluble protein antigens. Crit Rev Immunol 2001;21:121-31.

25 Vidal K, Samarut C, Magaud JP, et al. Unexpected lack of reactivity of allogeneic anti-la monoclonal antibodies with MHC class II molecules expressed by mouse intestinal epithelial cells. J Immunol 1993;151:4642-50.

26 Vincent-Schneider H, Stumptner-Cuvelette $P$, Lankar D, et al. Exosomes bearing HLA-DR 1 molecules need dendritic cells to efficiently stimulate specific T cells. Int Immunol 2002;14:713-22.

27 Denzer K, van Eijk M, Kleijmeer MJ, et al. Follicular dendritic cells carry MHC class II-expressing microvesicles at their surface. J Immunol 2000:165:1259-65.

28 Rescigno M, Urbano M, Valzasina B, et al. Dendritic cells express tight junction proteins and penetrate gut epithelial monolayers to sample bacteria. Nat Immunol $2001 ; 2: 361-7$

29 Alpan O, Rudomen G, Matzinger P. The role of dendritic cells, B cells, and M cells in gut-oriented immune responses. J Immunol 2001;166:4843-52. 